\title{
Complications from use of sodium hyaluronate (Healonid) in anterior segment surgery
}

\author{
S. P. B. PERCIVAL \\ From Scarborough Hospital
}

SUMMARY Sodium hyaluronate brings an important new advance to several techniques in ophthalmic microsurgery. Its use in 226 primary lens implantations is described, and it has been found to be safe and beneficial to both surgeon and patient. Apart from a one day rise of intraocular pressure, obviated by the routine use of timolol maleate or acetazolamide, it has been found in the dosage used to be free from complication.

Sodium hyaluronate was first used in ophthalmic surgery as a vitreous substitute more than 10 years ago $^{1}$ when its properties were shown to be elastic, highly viscous, yet nontoxic, noninflammatory, and nonantigenic. ${ }^{2}$ More recently Balazs, Miller, and Stegmann introduced its use into anterior segment surgery. ${ }^{3-5}$ The $1 \%$ solution (Pharmacia UK Ltd, Healonid) is at least 400000 times more viscous than aqueous yet will pass through the fine Rycroft cannula. It is totally transparent, and because of its high molecular weight it is nonosmotic. Because of these properties and the fact that it will maintain anterior chamber depth when air may not, it has been described as the ideal medium for closed chamber surgery. ${ }^{6}$

The particular assets of Healonid are that it will allow complex surgical manipulation in the anterior chamber, improving visibility while protecting the corneal endothelium and surrounding tissues from the trauma of surgical instrumentation. It may also be used to aid atraumatically the cleavage of iris synechiae or other adherent tissues. Thus Healonid has a place in the field of trauma ${ }^{78}$ (synechiolysis, extraction of corneal splinters penetrating the anterior chamber, anterior segment reconstruction), in keratoplasty ${ }^{49}$ (both for donor and recipient eye to protect endothelium), in filtration surgery ${ }^{5}$ (to prevent flat anterior chamber and hypotonia), in extracapsular cataract extraction ${ }^{56}$ (during capsulectomy and to protect endothelium from a hard lens nucleus),

Correspondence to S. P. B. Percival, FRCS, Department of Ophthalmology, Scarborough Hospital, Scarborough, North Yorkshire. and in the field of lens implantation ${ }^{4-69-13}$ (anterior chamber manipulation, protection of endothelium, synechiolysis, iris suturing, and to maintain anterior chamber depth for secondary procedures such as keratoplasty and filtration surgery). Healonid may also be used in retinal detachment surgery ${ }^{14}$ is (for internal tamponade).

This communication seeks to assess the possible complications that may be attributed to Healonid in the field of primary lens implantation.

\section{Material and methods}

Three hundred and thirty-four consecutive lens replacements were performed during the 29 months commencing January 1980. 244 followed planned extracapsular nucleus extraction (as described previously ${ }^{6}$ ) with an age range $39-88$, mean 73 years; 90 followed intracapsular cryoextraction after zonulysis, with an age range 56-94, mean 77 years. Healonid was used for every case when it was available. For standardisation, between $0.2 \mathrm{ml}$ and $0.3 \mathrm{ml}$ was used per eye whether or not the particular eye needed it. There was therefore no patient selection for the use of Healonid. No attempts were made to aspirate Healonid at the end of surgery. It was used in a total of 226 eyes to deepen the anterior chamber prior to lens implantation. Of these, 164 followed extracapsular extraction when it was also used to maintain the anterior chamber during capsulectomy and inserted to provide a cushion between lens nucleus and cornea during extraction, and 62 followed cryoextraction, 46 of which also necessitated an iris suture, placed as described by the author ${ }^{12}$ 
Table 1 Postoperative ocular hypertension in 334 eyes

\begin{tabular}{|c|c|c|c|c|}
\hline \multirow[t]{2}{*}{ Eyes } & \multicolumn{2}{|l|}{ First day } & \multicolumn{2}{|c|}{ Mean IOP $(\mathrm{mmHg})$} \\
\hline & $I O P>30 \mathrm{mmHg}$ & $5 \mathrm{~mm}>$ preop. & 1st day & 3rd day \\
\hline $\begin{array}{l}108 \text { Controls } \\
54 \text { Healonid } \\
109 \text { Healonid + acetazolamide } \\
63 \text { Healonid + timolol }\end{array}$ & $\begin{array}{l}11(10 \%) \\
17(31 \%)^{* *} \\
8(7 \%)^{* *} \\
7(11 \%)^{*}\end{array}$ & $\begin{array}{l}24(22 \%) \\
31(57 \%)^{* *} \\
38(35 \%)^{*} \\
20(32 \%)^{*}\end{array}$ & $\begin{array}{l}18 \cdot 9 \\
25 \cdot 6 \\
19 \cdot 7 \\
20 \cdot 0\end{array}$ & $\begin{array}{l}15 \cdot 7 \\
15 \cdot 5 \\
14 \cdot 4 \\
14 \cdot 2\end{array}$ \\
\hline
\end{tabular}

$I O P=$ intraocular pressure.

${ }^{*} \mathrm{p}<0 \cdot 01 ;{ }^{* *} \mathrm{p}<0 \cdot 001$.

under Healonid with the chamber closed. There was only one case of aborted lens implantation during the 29 months, this being for reasons of vitreous loss.

Postoperative routine included careful slit-lamp examination by the author on the first, third, and fifteenth postoperative days and more frequently when necessary. Raised intraocular pressure was treated with topical timolol maleate or systemic acetazolamide or both in combination. However, following the initial trial with 54 cases, in order to obviate further ocular hypertension, 2 subgroups of patients receiving Healonid were made: $(a)$ during 1981109 patients were given routine intramuscular acetazolamide $500 \mathrm{mg} 4$ hours after completion of surgery followed by tablets $250 \mathrm{mg}$ q.d.s. for 2 days; (b) during 198263 eyes received timolol maleate $0.25 \%$ drops on completion of surgery followed by b.d. application for 2 days. Particular attention was paid to development of uveitis, wound healing, and ocular hypertension.

\section{POSTOPERATIVE OCULAR HYPERTENSION}

Healonid leaves the anterior chamber by way of the aqueous outflow channels, ${ }^{16}$ but the viscosity has to be reduced by dilution with aqueous before this hydrophilic substance may run through the trabecular meshwork. Intraocular pressure may rise therefore if excessive amounts of Healonid remain in the anterior chamber at the end of surgery.

One hundred and eight eyes did not receive Healonid or any routine ocular hypotensive. These acted as controls (Table 1). Of 54 eyes initially receiving Healonid (all were extracapsular extractions) $57 \%$ showed a rise of intraocular pressure $5 \mathrm{~mm}$ or more than the preoperative level. The first day applanation was over $30 \mathrm{mmHg}$ in $31 \%$ and the mean intraocular pressure was $25.6 \mathrm{mmHg}$ compared with $18.9 \mathrm{mmHg}$ in the control group.

\section{Results}

In a double-blind trial on 21 normal subjects guttae timolol $0.5 \%$ has been shown to reduce the aqueous flow by $33 \%$ and tab. acetazolamide $250 \mathrm{mg}$ by $27 \% .{ }^{17}$ Of the 109 eyes in the present study receiving Healonid and routine postoperative acetazolamide the mean first-day intraocular pressure was $19 \cdot 7$ $\mathrm{mmHg}$, and only $7 \%$ of readings were over $30 \mathrm{mmHg}$. Of the 63 eyes receiving Healonid and routine timolol the corresponding figures were 20.0 and $11 \%$ respectively.

These findings confirm the value of acetazolamide and timolol in reducing aqueous secretion, and Table 1 also shows that by the third postoperative day there was little difference in mean intraocular pressure between the different groups, the marginally higher mean pressure found in controls being explained by the fact that these eyes were less likely to have been offered treatment.

No significant difference was found between intracapsular and extracapsular eyes (Table 2). There were no cases of pupil block glaucoma among the groups receiving Healonid.

\section{Discussion}

\section{UVEITIS}

On the first day slit-lamp examination often gives the appearance of a plastic anterior uveitis in an eye containing Healonid. However, this is due to the presence of Healonid holding cells in suspension. Flecks of blood may also be seen held in suspension due to rouleaux caused by altered electrostatic charge on red blood cells. These appearances vanish by the third day and do not require specific treatment. $7 \%$ of

Table 2 Incidence of raised intraocular pressure on first postoperative day (the initial 54 extracapsular eyes receiving Healonid are excluded)

\begin{tabular}{clc}
\hline & \multicolumn{1}{c}{$I O P>30 \mathrm{mmHg}$} & $5 \mathrm{~mm}>$ preop. \\
\hline Controls 28 IC & $3(11 \%)$ & $5(18 \%)$ \\
80 EC & $8(10 \%)$ & $19(24 \%)$ \\
Healonid 62 IC & $6(10 \%)$ & $26(42 \%)$ \\
110 EC & $9(8 \%)$ & $31(28 \%)$ \\
\hline
\end{tabular}

$\mathrm{IOP}=$ intraocular pressure. $\mathrm{IC}=$ intracapsular. $\mathrm{EC}=$ extracapsular. 
Healonid eyes and $8 \%$ of controls were recorded as having a more severe uveitis than is expected during the first postoperative week, but there were no cases of hypopyon or of developing keratic precipitates. There were no cases of spluttering hyphaema or of the uveitis-glaucoma-hyphaema (UGH) syndrome.

\section{WOUND HEALING}

There were no eyes in which delayed healing or improper apposition could be attributed to Healonid. A disadvantage of Healonid is that at the end of surgery it is more difficult to assess whether a wound is water-tight than when the anterior chamber is reconstituted purely with salt solution. This is of particular importance during keratoplasty, ${ }^{9}$ and alternative methods of reconstituting the anterior chamber should be preferred during the final phases of surgery.

\section{VISUAL ACUITY}

After 17 patients had been excluded because of preexisting visual defects unrelated to cataract all eyes were seeing $6 / 12$ or better at the final point of followup except for the following: (i) macular oedema: 5 intracapsular eyes and one extracapsular eye were seeing $6 / 18$ or less, 4 had received Healonid and two had not; (ii) retinal detachment: one intracapsular eye; (iii) corneal decompensation: one extracapsular eye that had not received Healonid.

\section{CONCLUSION}

The use of sodium hyaluronate is perhaps the single most important advance to be seen in anterior segment surgery in 10 years. It is safe and free from complications except an ocular hypertensive effect, which generally lasts for less than 3 days. This may be obviated by the routine use of postoperative timolol maleate or acetazolamide or both in combination.

\section{References}

1 Algrere $P$. Intravitreal injection of high molecular weight hyaluronic acid in retinal detachment surgery. Acta Ophthalmol (Kbh) 1971; 49: 975-7.

2 Balazs EA, Freeman MI, Klöti R, Meyer-Schwickerath G. Regnault F. Sweeney DH. Hyaluronic acid and replacement of vitreous and aqueous humour. Mod Probl Ophthalmol 1972; 10: 3-6.

3 Balazs EA. Miller D. Stegmann R. Viscosurgery and the use of Na-hyaluronate in intraocular lens implantation. Presented at the International Congress and First Film Festival on Intraocular lens implantation. Cannes, France. May 1979.

4 Miller D. Stegmann R. Use of Na-hyaluronate in anterior segment eye surgery. Am Intraoc Implant Soc J 1980; 6: 13-5.

5 Pape LG, Balazs EA. The use of Na-hyaluronate in human anterior segment surgery. Ophthalmology 1980; 87: 699-705.

6 Percival SPB. Protective role of Healon during lens implantation. Trans Ophthalmol Soc UK 1981; 101: 77-8.

7 Stegmann R. Communication to UK Intraocular Implant Society. Southend. England. May 1981.

8 Percival SPB. Communication to South African Ophthalmological Society, Cape Town, SA. March 1982.

9 Polack FM. Demong T. Santaella H. Sodium hyaluronate in keratoplasty. Am Acad Ophthalmol. Chicago, Ill, November 1980 .

10 Miller D. Stegmann R. Use of sodium hyaluronate in human IOL implantation. Ann Ophthalmol 1981; 13: 811-5.

11 Pape LG. Intracapsular and extracapsular technique of lens implantation with Healon. Am Intraoc Implant Soc J 1980; 6: 342-3.

12 Percival SPB. Experience with the Boberg Ans lens and sodium hyaluronate. Trans Ophthalmol Soc UK in press.

13 Choyce DP. Healon in anterior chamber lens implantation. Am Intraoc Implant Soc J 1981; 7: 138-9.

14 Stenkula S, Ivert L, Gislason I, Tornquist R, Weijdegard L. The use of sodium hyaluronate in the treatment of retinal detachment. Ophthalmic Surg 1981; 12: 435-7.

15 Swartz M, Olson RJ, Pingree GC. Sakauye C. The use of anterior chamber $\mathrm{Na}$-hyaluronate in a pseudophakic patient requiring intravitreal air during retinal reattachment surgery. Ophthaimic Surg 1981; 12: 98-9.

16 Yamaguchi T. Polack FM. Electron microscopy of $\mathrm{Na}$ hyaluronate in the anterior chamber of rabbit eyes. Microsurgical conference, Orlando, Fla, October 1979.

17 Dailey RA, Brubaker RJ. Bourne WM. The effects of timolol maleate and acetazolamide on the rate of aqueous formation in normal human subjects. Am J Ophthalmol 1982; 93: 232-7. 